\title{
Identifikasi Ketersediaan dan Kualitas Sarana Prasarana Lingkungan di Urban Fringe Area Kelurahan Pudakpayung
}

\author{
Ajeng Dwi Handayani' ${ }^{1}$ \\ Jurusan Perencanaan Wilayah dan Kota \\ Universitas Diponegoro, Semarang, Indonesia \\ Nany Yuliastuti \\ Dosen Jurusan Perencanaan Wilayah dan Kota \\ Universitas Diponegoro, Semarang, Indonesia \\ Artikel Masuk : 30 September 2014 \\ Artikel Diterima : 18 November 2014
}

\begin{abstract}
Abstrak: Kelurahan Pudakpayung adalah kelurahan paling selatan di Kecamatan Banyumanik Kota Semarang. Daerah ini termasuk sebagai daerah pinggiran kota yang pertambahan jumlah penduduk dan pertambahan luas lahan permukimannya cukup tinggi. Tetapi tidak didukung dengan sarana prasarana lingkungan yang baik. Untuk itu perlu dilakukannya penelitian untuk melihat ketersediaan dan kualitas sarana prasarana lingkungan yang ada di daerah pinggiran kota ini. Sehingga dapat memberikan sebuah rekomendasi terkait ketersediaan dan kualitas sarana prasarana lingkungan khususnya di daerah pinggiran kota. Penelitian ini akan mengidentifikasi perubahan pola lahan permukiman dan kemudian mengidentifikasi ketersediaan, kualitas, dan penyebaran sarana prasarana lingkungan permukiman. Metode penelitian yang digunakan pada penelitian ini yaitu metode deskriptif kuantitatif. Analisis yang digunakan yaitu analisis deskriptif kuantitatif dengan ketentuan SNI 03-1733-2004, skoring dengan skala Likert, dan pemetaan spasial. Hasil dari penelitian ini menunjukkan presentase perubahan pola lahan terbangun serta ketersedian, kualitas, dan persebaran dari setiap sarana prasarana lingkungan.
\end{abstract}

Kata Kunci: Daerah Pinggiran Kota. Kelurahan Pudakpayung, Prasarana Lingkungan, Sarana Lingkungan

\begin{abstract}
Pudakpayung Sub District is the southest in Banyumanik District of Semarang City. This area is a Urban Fringe Area with high population growth and development area for human settlement. But not supported by good facilities and infrastructure. This research is aiming to see the availability and quality of facilities and infrastructure in this urban fringe area. So, this research can give the recommendation about availability and quality of facilities and infrastructure, especially in urban fringe area. This research will identify changes the pattern of human settlement and then identify the availability, quality, and distribution of neighborhoods facilities and infrastructure. The research method used in this research is quantitative descriptive method. The analysis uses the quantitative descriptive analysis with the provisions of SNI 03-1733-2004, scoring with a Likert scale, and spatial mapping. The
\end{abstract}

\footnotetext{
${ }^{1}$ Korespondensi Penulis: Jurusan Perencanaan Wilayah dan Kota, Fakultas Teknik, Universitas Diponegoro, Semarang email: rescue.ajeng@gmail.com
} 
result of this research indicate changes the pattern of land up and indicate the availability, quality, and distribution of every facilities and infrastructure.

Keywords: Pudakpayung Sub District, Environment Facilities, Environment Infrastructure, Urban Fringe Area.

\section{Pendahuluan}

Fenomena pesatnya pertumbuhan kawasan pinggiran yang melanda Kota Semarang berlangsung sejalan dengan pertumbuhan jumlah penduduk perkotaan Semarang yang meningkat dengan cepat tiap tahunnya. Hal ini terjadi karena meningkatnya kebutuhan manusia akan lahan untuk bermukim sehingga lahan yang sudah sangat minim di pusat kota menjadi semakin sulit untuk diakses. Hal ini yang membuat kawasan pinggiran berkembang dan menjadi sebuah aset yang menguntungkan. Masyarakat akan melirik kawasan pinggiran sebagai tempat hunian baru dan berharap pemerintah akan menyediakan sarana prasarana permukiman di kemudian hari.

Dituangkan dalam UU Perumahan dan Kawasan Permukiman tahun 2011, pasal 1 ayat 5 , bahwa permukiman harus menyediaan unsur tempat tingggal yang lengkap dengan berbagai sarana dan prasarana. Namun pembangunan fasilitas dan pelayanan sosial serta prasarana lingkungan di Indonesia pada umumnya kurang mendapat perhatian (Budiharjo, 1991). Hal tersebut sejalan dengan banyak ditemukan isu-isu serupa di beberapa daerah pinggiran di Indonesia. Diambil dari situs berita di Kota Riau, www.m.riaupos.co (2013) bahwa "Desa pinggiran sering terabaikan. Desa pinggiran terisolasi dan desa pinggiran miskin infrastruktur". Hal ini dirasa tidak seimbang, manakala permukiman daerah pinggiran terus tumbuh namun infrastruktur penunjang permukiman masih sangat minim.

Seperti halnya di Kelurahan Pudakpayung Kecamatan Banyumanik Kota Semarang. Kelurahan Pudakpayung yang merupakan daerah pinggiran ini mengalami pertambahan jumlah penduduk, rumah, RW, RT, dan perluasan lahan yang cukup tinggi. Adapun pertambahan yang terjadi sebagai berikut :

Tabel 1. Perubahan Jumlah Dan Luasan Di Kelurahan Pudakpayung

\begin{tabular}{|c|c|c|c|}
\hline KETERANGAN & 2004 & 2009 & 2014 \\
\hline Jumlah Penduduk & $\begin{array}{c}10.927 \\
\text { jiwa }\end{array}$ & $\begin{array}{c}18.838 \\
\text { jiwa }\end{array}$ & $\begin{array}{c}21.927 \\
\text { jiwa }\end{array}$ \\
\hline Jumlah Rumah & $\begin{array}{c}2.264 \\
\text { unit }\end{array}$ & $\begin{array}{c}2.867 \\
\text { unit }\end{array}$ & $\begin{array}{c}3.952 \\
\text { unit }\end{array}$ \\
\hline Jumlah RW & 14 & 15 & 16 \\
\hline Jumlah RT & 93 & 118 & 124 \\
\hline $\begin{array}{c}\text { Luas Tanah Sawah dan } \\
\text { Tanah Kering }\end{array}$ & $\begin{array}{c}392,93 \\
\mathrm{Ha}\end{array}$ & $\begin{array}{c}297,72 \\
\mathrm{Ha}\end{array}$ & $\begin{array}{c}228,12 \\
\mathrm{Ha}\end{array}$ \\
\hline
\end{tabular}

Hal ini cukup membuktikan bahwa kelurahan ini sangat diminati oleh masyarakat sebagai daerah permukiman. Dari perluasan dan pertambahan permukiman ini kemudian muncul permasalahan-permasalahan terkait sarana dan prasarana lingkungan. Seperti kurangnya sarana pendidikan dan tempat/ ruang bersosialisasi untuk mengadakan acara serta sistem persampahan dan sistem jalan yang kurang baik.

Dengan semakin meningkatnya kepadatan lingkungan permukiman di daerah pinggiran kota (Urban Fringe Arena) namun tidak didukung dengan ketersediaan dan kualitas sarana dan prasarana lingkungan yang baik maka akan menjadikan daerah 
tersebut terisolasi dan tidak dapat berkembang. Hal ini yang kemudian menjadi suatu pertanyaan besar bagaimana ketersediaan dan kualitas sarana prasarana lingkungan di Urban Fringe Area Kelurahan Pudakpayung. Sehingga perlu dianalisis perubahan pola lahan permukiman di Kelurahan Pudakpayung dan menganalisis ketersediaan, kualitas, dan persebaran dari saran prasarana lingkungan yang kemudian menjadi rekomendasi untuk pihak terkait dalam menyediakan dan melengkapi dasar kebutuhan masyarakat dalam bermukim ini.

\section{Metode Penelitian}

Penelitian mengenai identifikasi ketersediaan dan kualitas sarana prasarana lingkungan di Urban Fringe Area Kelurahan Pudakpayung ini menggunakan metode penelitian kuantitatif. Metode kuantitatif merupakan metode yang digunakan untuk menganalisis data-data tersaji dalam bentuk angka dan terukur. Metode ini lebih akurat dibandingkan dengan metode kualitatif, karena menunjukkan bukti numerik yang kuat dan melibatkan perhitungan yang bersifat matematis. Jenis metode kuantitatif didasari pada logika empirik yang dilakukan secara formal dan obyektif dengan proses kerja yang sistematis. Menurut Sugiyono (2013:13) pendekatan kuantitatif ini dinamakan metode tradisional, karena sudah cukup lama digunakan sehingga sudah mentradisi sebagai metode untuk penelitian. Sebagai metode ilmiah/ scientifik maka harus memenuhi kaidahkaidah ilmiah yaitu kongkrit, obyektif, terukur, rasional dan sistematis.

Dalam penelitian identifikasi ketersediaan dan kualitas sarana prasarana lingkungan di Urban Fringe Area Kelurahan Pudakpayung ini nantinya akan dianalisis menggunakan metode desktiptif kuantitatif berdasarkan hasil kuisioner dan obeservasi yang didapatkan dilapangan untuk menentukan ketersediaan, kualitas, dan persebaran sarana prasarana lingkungan di Urban Fringe Area Kelurahan Pudakpayung. Metode deskriptif digunakan untuk meneliti sekompok manusia, objek, kondisi, pemikiran atau peristiwa yang terjadi di masa sekarang dengan tujuan membuat deskripsi secara sistematis mengenai fakta-fakta (Nasir 2003 dalam Azahro 2013). Adapun tahapan dalam penelitian ini adalah merumuskan masalah (problem statement), menentukan tujuan penelitian, pembatasan substansi dan spasial, merumuskan kerangka teori, merumuskan hipotesis baik secara eksplisit maupun implisit, pengumpulan data, analisis statistik, interpretasi hasil, rekomendasi dan pelaporan.

Metode deskriptif ini dianggap sesuai dengan penelitian yang dilakukan dimana penyusun hanya mencoba mengidentifikasi ketersediaan dan kualitas sarana prasarana lingkungan di daerah pinggiran seperti Kelurahan Pudakpayung dengan melihat dan menganalisis perubahan pola lahan permukiman, serta melihat dan menganalisis ketersediaan, kualitas, dan persebaran sarana prasarana lingkungan permukimannya.

Teknik sampling yang digunakan dalam penelitian ini adalah probabilitas sampling. Jenis pengambilan sampel yang dipilih dalam penelitian ini adalah Random Sampling dan Stratified Random Sampling. Pengambilan sampel dengan cara memberikan kesempatan yang sama kepada semua populasi yang ada di wilayah penelitian untuk menjadi sampel atau responden dan terlebih dahulu sudah dilakukan stratifikasi dalam mengambil sampel pada masing-masing wilayah yang akan diambil sampel. Namun, karena banyaknya jumlah populasi maka digunakan sistem sampling dalam penelitian ini, sehingga dengan model ini semua sampel yang diambil dapat mewakili populasi dan sesuai dengan tujuan penelitian yang diharapkan (Sugiyono, 2013).

Dalam penetuan jumlah sampel yang diambil, digunakan Rumus Taro Yamane (www.opiniwikuspaces.com dalam Irhansyah, 2010): 


$$
\begin{aligned}
& \mathrm{n}=\frac{\mathrm{N}}{\mathrm{N} \mathrm{d}^{2}+1} \\
& \text { Keterangan: } \\
& \mathrm{n}=\text { jumlah sampel } \\
& \mathrm{N}=\text { jumlah populasi } \\
& \mathrm{d}=\text { derajat kesesuaian }
\end{aligned}
$$

Derajat kesesuaian yang dipakai dalam menentukan jumlah sampel adalah $10 \%$. Hal ini menunjukkan bahwa tingkat kecermatan studi dapat dikategorikan cermat, untuk tingkat kepercayaan 90\%. Dengan memperhitungkan rumah tangga sebagai target responden, maka data yang digunakan untuk menghitung sampel adalah jumlah kepala keluarga dengan perhitungan sebagai berikut :

$$
\begin{aligned}
& n=\frac{5.689}{5.689(10 \%)^{2}+1} \\
& =98,21 \rightarrow 99 \text { sampel }
\end{aligned}
$$

Dalam penelitian ini jumlah responden yang akan dijadikan sampel adalah 98 orang. Jumlah tersebut dianggap sudah mewakili dari jumlah populasi (Kepala Keluarga) yang ada di Kelurahan Pudakpayung untuk dapat digunakan dalam mengidentifikasi ketersediaan dan kualitas sarana prasarana lingkungan di Urban Fringe Area Kelurahan Pudakpayung.

Metode analisis diperlukan dalam analisis data penelitian. Metode analisis menjelaskan mengenai teknik data. Analisis yang digunakan antara lain adalah analisis deskriptif kuantitatif dengan skala Likert, analisis deskriptif kuantitatif dengan ketentuan SNI 03-1733-2004, dan deskriptif kuantitatif dengan pemetaan spasial.

Analisis deskriptif kuantitatif adalah analisis yang digunakan untuk menjelaskan data yang diperoleh di lapangan. Data tersebut dianggap mampu mewakili seluruh anggota populasi. Analisis deskriptif kuantitatif digunakan untuk menjelaskan data yang berupa data nominal, ordinal maupun interval/rasio agar data menjadi lebih mudah dibaca. Teknik analisis deskriptif kuantitatif meliputi kegiatan dalam mengelompokkan, mengurutkan atau memisahkan bagian yang dianggap relevan dan penting dari keseluruhan data. Kemudian dilakukan analisis dengan memberikan skor/bobot pada masing-masing variabel penelitian yang akan diteliti. Dalam melakukan skoring perlu ada pembagian kategori agar mempermudahkan dalam memberi skor. Dalam penelitian ini variabel yang akan diberi skor adalah yang berhubungan dengan kualitas sarana dan prasarana lingkungan permukiman dari sisi masyarakat.

Dalam menentukan skor penilaian merujuk pada skala Likert yang dapat menggunakan jenjang 3, 5 maupun 7 tergantung pada populasi penelitian. Dan dalam penelitian ini akan menggunakan jenjang skor 3 untuk menilai kualitas sarana dan prasarana lingkungan permukiman. Pemberian skor didasarkan pada kelas kondisi baik, kondisi kurang baik, dan kondisi buruk. Skor 1 untuk menggambarkan kondisi buruk dan skor 3 untuk menggambarkan kondisi baik. Sehingga nilai tinggi akan menggambarkan kondisi sarana dan prasarana di Kelurahan Pudakpayung dalam keadaan baik dan nilai rendah akan menggambarkan sebaliknya. Sedangkan untuk rentang skor, maka dapat dicari dengan rumus:

$$
\text { Rentang skor }=\frac{\text { Skor tertinggi }- \text { skor terendah }}{\text { Jumlah jenjang skor }}
$$




$$
\begin{aligned}
& \text { Rentang skor }=\frac{3-1}{3} \\
& \text { Rentang skor }=0,7
\end{aligned}
$$

Sehingga jarak kelas interval antara skor Kondisi Baik, skor Kondisi Kurang Baik, dan skor Kondisi Buruk adalah sebesar 0,7. Mengingat skor terendah adalah 1, maka kelas interval pada skor Kondisi Buruk adalah 1 dan 1+0,7, dan seterusnya.

Sedangkan untuk teknik deskriptif kuantitatif dengan ketentuan SNI 03-1733-2004 adalah untuk mendeskripsikan jumlah sarana eksisting yang ada di lapangan dengan jumlah sarana yang seharusnya ada sesuai standar serta untuk mendeskripsikan gambaran persebaran dan radius pencapaian dari setiap sarana lingkungan permukiman.

Dan untuk analisis deskriptif kuantitatif dengan pemetaan spasial adalah analisis yang akan menggambarkan pola perubahan lahan permukiman di Kelurahan Pudakpayung. Selain itu untuk hasil analisis persebaran dan radius pencapaian sarana juga akan dipetakan secara spasial sesuai dengan standar yang berlaku. Pemetaan ini berfungsi untuk mempermudahkan pembacaan data hasil analisis apabila dikaitkan dengan lokasi penelitian. Hasil analisis skoring juga akan dipetakan secara spasial untuk memperjelas lokasi mana saja yang kualitas prasarananya baik, kurang baik, dan buruk

\section{Hasil Dan Pembahasan}

Penelitian yang berjudul Identifikasi Ketersediaan dan Kualitas Sarana Prasarana Lingkungan di Urban Fringe Area Kelurahan Pudakpayung ini memperoleh beberapa hasil yang akan dijelaskan satu per satu. Berikut ini akan memaparkan hasil dan pembahasan pada masing-masing variabel, yaitu perubahan pola lahan permukiman, ketersediaan sarana prasarana lingkungan permukiman, kualitas sarana prasarana lingkungan permukiman, dan persebaran sarana prasarana lingkungan permukiman.

\section{Analisis Perubahan Pola Lahan Permukiman}

Dari analisis perubahan pola lahan permukiman yang telah dilakukan dapat diketahui bahwa Kelurahan Pudakpayung yang merupakan daerah pinggiran kota mengalam pertumbuhan lahan terbangun yang pesat yaitu sebesar 8,3\% pada tahun 2004 hingga 2009, dan 13,3\% pada tahun 2009 hingga 2014. Dengan pertambahan tertinggi berada di RW VI sebesar 27\% pada tahun 2004-2009 dan 22\% di RW I pada tahun 2009-2014.

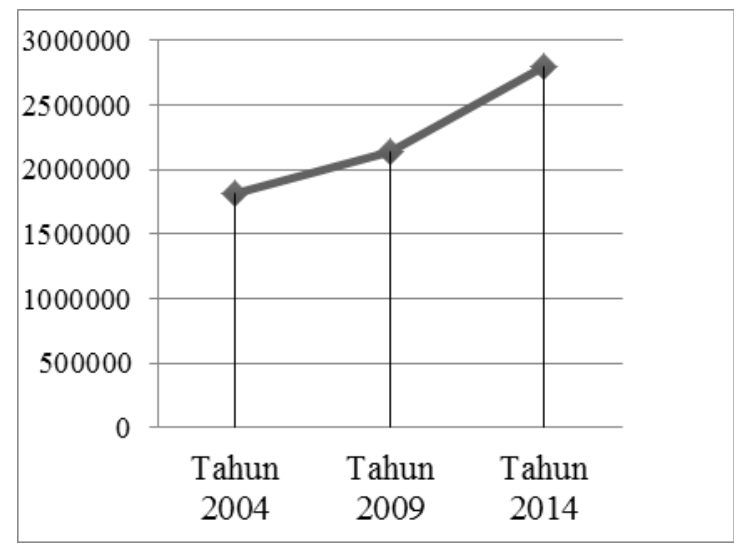

Gambar 1. Grafik Perubahan Luas Lahan Terbangun di Kelurahan Pudakpayung 
Lahan terbangun tersebut sebagian besar digunakan untuk lahan permukiman. Sedangkan untuk jumlah rumah di Kelurahan Pudakpayung meningkat 11,7\% pada tahun 2004 hingga 2009, dan 15,9\% pada tahun 2009 hingga 2014 .

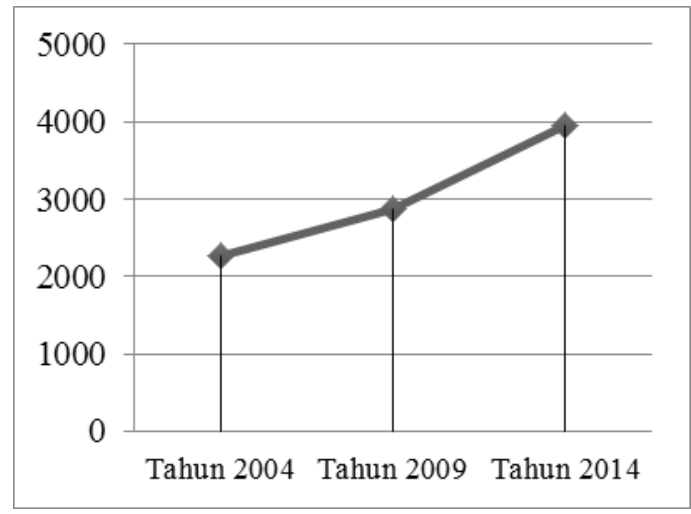

\section{Gambar 2. Grafik Perubahan Jumlah Rumah di Kelurahan Pudakpayung}

\section{Analisis Ketersediaan Sarana Prasarana Lingkungan Permukiman}

Dari analisis ketersediaan sarana prasarana lingkungan permukiman yang telah dilakukan dapat diketahui bahwa:

1. Ketersediaan Sarana Lingkungan sebagai berikut :

Tabel 2. Jumlah Unit Sarana Eksisting Dan Jumlah Unit Sesuai SNI

\begin{tabular}{|c|c|c|c|}
\hline No & Unit Sarana & Jumlah Eksisting (Unit) & $\begin{array}{c}\text { Jumlah Seharusnya (Sesuai } \\
\text { Ketentuan SNI 03-1733-2004) } \\
\text { (Unit) }\end{array}$ \\
\hline \multirow{6}{*}{1} & \multicolumn{3}{|c|}{ Sarana Pendidikan } \\
\hline & - $\mathrm{PAUD} / \mathrm{TK}$ & 17 & 17 \\
\hline & - SD & 3 & 14 \\
\hline & - SLTP & 2 & 4 \\
\hline & - $\mathrm{SMU}$ & 1 & 4 \\
\hline & - Tamana Bacaan & 5 & 9 \\
\hline \multirow{5}{*}{2} & \multicolumn{3}{|c|}{ Sarana Kesehatan } \\
\hline & - Posyandu & 23 & 17 \\
\hline & - Balai Pengobatan Warga & 1 & 9 \\
\hline & - Puskesmas & 1 & (minimal ada 1$)$ \\
\hline & - Tempat Praktek Dokter & 8 & 4 \\
\hline \multirow{5}{*}{3} & \multicolumn{3}{|c|}{ Sarana Peribadatan } \\
\hline & - Musholla/ Langgar & 14 & 88 \\
\hline & - Masjid Warga & 20 & 9 \\
\hline & - Gereja/ Sanggar & 10 & - \\
\hline & - Pura & 1 & - \\
\hline \multirow{3}{*}{4} & \multicolumn{3}{|c|}{ Sarana Perdagangan dan Niaga } \\
\hline & - Toko/ Warung & 186 & 87 \\
\hline & - Pertokoan & 29 & 3 \\
\hline \multirow{3}{*}{5} & \multicolumn{3}{|c|}{$\begin{array}{l}\text { Sarana Kebudayaan dan Rekreasi } \\
\end{array}$} \\
\hline & - Balai Warga/ Balai Pertemuan & 13 & 9 \\
\hline & - Gedung Serbaguna & 2 & (minimal ada 1 ) \\
\hline
\end{tabular}




\begin{tabular}{|c|c|c|c|}
\hline No & Unit Sarana & Jumlah Eksisting (Unit) & $\begin{array}{c}\text { Jumlah Seharusnya (Sesuai } \\
\text { Ketentuan SNI 03-1733-2004) } \\
\text { (Unit) }\end{array}$ \\
\hline \multirow{4}{*}{6} & \multicolumn{3}{|c|}{ Sarana Ruang Terbuka, Taman, dan Lapangan Olahraga } \\
\hline & - Taman/ Tempat Bermain & 3 & 88 dan 9 \\
\hline & - Lapangan Olahraga & 23 & (minimal ada 1) \\
\hline & - Makam & 11 & (minimal ada 1$)$ \\
\hline
\end{tabular}

Ketersediaan sebagian besar sarana pendidikan belum sesuai standar. Masih membutuhkan 11 unit SD, 2 unit SLTP, 3 unit SLTA, dan 4 unit Taman Bacaan lagi. Sedangkan untuk PAUD/ TK sudah sesuai. Ketersediaan beberapa sarana kesehatan sudah sesuai standar, seperti Posyandu, Puskesmas, dan Tempat Praktek Dokter.

Sedangkan untuk Balai Pengobatan masih membutuhkan 8 unit lagi. Ketersediaan beberapa sarana peribadatan sudah sesuai standar, seperti Masjid warga, Gereja/ Sanggar, dan Vihara. Sedangkan untuk Musholla/ Langgar masih membutuhkan 74 unit lagi. Ketersediaan seluruh sarana perdagangan dan niaga sudah sesuai standar. Ketersediaan seluruh sarana kebudayaan dan rekreasi sudah sesuai standar. Dan ketersediaan beberapa sarana ruang terbuka, taman, dan lapangan olahraga sudah sesuai standar, seperti Lapangan Olahraga dan Makam. Sedangkan untuk Taman/ Tempat Bermain masih membutuhkan 6 atau 85 unit lagi.

2. Prasarana Lingkungan sudah tersedia di Kelurahan Pudakpayung. Seperti Jaringan Drainase, Jaringan Sanitasi, Jaringan Airs Bersih, Jaringan Jalan, dan Jaringan Persampahan. Sedangakan untuk Jaringan Transportasi Lokal di Kelurahan Pudakpayung tidak tersedia, walaupun pernah beroperasi angkutan umum berupa bus pada tahun 1997 dan berhenti pada tahun 2003 karena beberapa alasan.

\section{Analisis Kualitas Sarana Prasarana Lingkungan Permukiman}

Dari analisis kualitas sarana prasarana lingkungan permukiman yang telah dilakukan dapat diketahui bahwa:

1. Kualitas Sarana Lingkungan sebagai berikut :

Tabel 3. Nilai Skoring Sarana Lingkungan

\begin{tabular}{|c|c|c|c|c|c|c|}
\hline \multirow[b]{2}{*}{ Keterangan } & \multicolumn{6}{|c|}{ Sarana } \\
\hline & Pendidikan & Kesehatan & Peribadatan & $\begin{array}{l}\text { Perdagangan } \\
\text { dan Niaga }\end{array}$ & $\begin{array}{l}\text { Kebudayanan } \\
\text { dan Rekreasi }\end{array}$ & $\begin{array}{c}\text { Ruang } \\
\text { Terbuka, } \\
\text { Taman, } \\
\text { dan } \\
\text { Lapangan } \\
\text { Olahraga } \\
\end{array}$ \\
\hline $\begin{array}{c}\text { Total } \\
\text { Skoring }\end{array}$ & 66 & 76 & 123 & 645 & 32 & 93 \\
\hline $\begin{array}{c}\text { Jumlah } \\
\text { Unit }\end{array}$ & 28 & 33 & 45 & 215 & 15 & 37 \\
\hline $\begin{array}{c}\text { Nilai } \\
\text { Skoring }\end{array}$ & $\begin{array}{c}2,3 \\
\text { (kurang } \\
\text { baik) }\end{array}$ & $\begin{array}{c}2,3 \\
\text { (kurang } \\
\text { baik) }\end{array}$ & 2,7 (baik) & 3 (baik) & $\begin{array}{l}2,1 \text { (kurang } \\
\text { baik) }\end{array}$ & 2,5 (baik) \\
\hline
\end{tabular}

Secara keseluruhan, dapat dilihat bahwa kualitas dari sarana peribadatan serta sarana ruang terbuka, taman, dan lapangan olahraga di Kelurahan Paudakpayung rata-rata sudah BAIK 
sedangkan kualitas sarana pendidikan, sarana kesehatan, dan sarana kebudayaan dan rekreasi di Kelurahan Pudakpayung rata-rata masih KURANG BAIK. Dengan rincian unit sarana yang berkualitas baik adalah SD, SLTP, SLTA, Taman Bacaan, Puskesmas, Tempat Praktek Dokter, Musholla/ Langgar, Masjid Warga, Gereja/ Sanggar, Vihara, Toko/ Warung, Pertokoan, Gedung Serbaguna, Taman/ Tempat bermain, dan Makam.

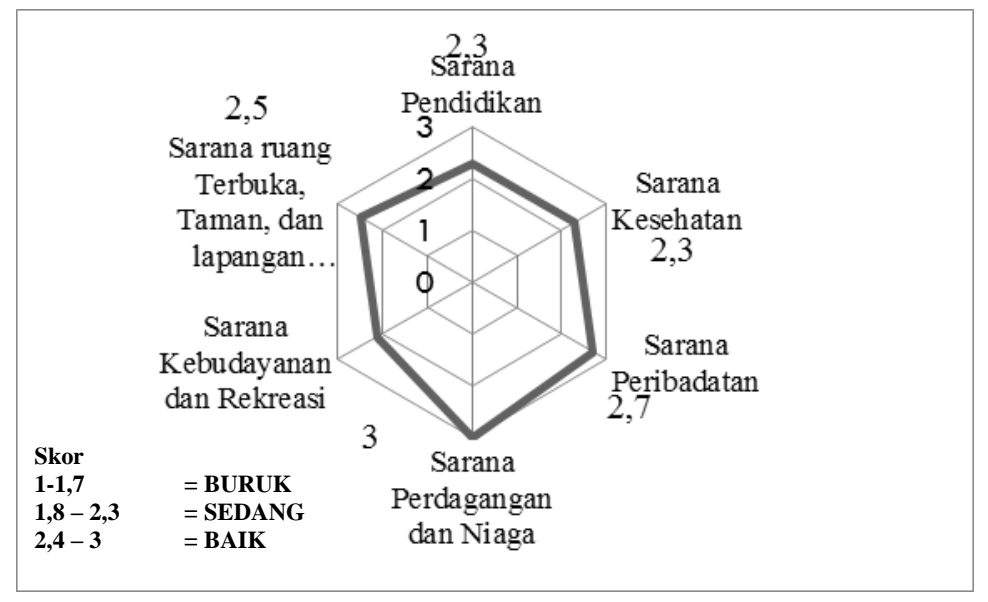

\section{Gambar 3. Diagram Kondisi Sarana di Kelurahan Pudakpayung}

Sehingga perlu untuk diadakannya peningkatan kualitas untuk sarana yang masih kurang baik, baik dari fisik bangunan maupun non fisik. Sedangkan untuk sarana yang sudah baik tetap harus dijaga kualitasnya dan ditingkat terus agar dapat menjadi percontohan kelurahan pinggiran kota yang baik.

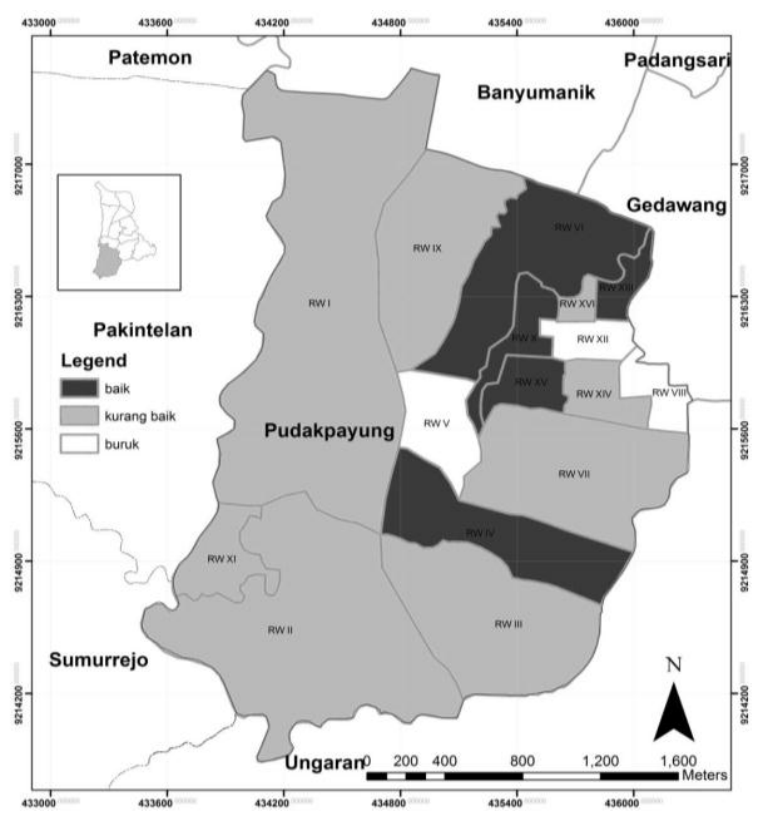

Gambar 4. Peta Kualitas Sarana Lingkungan di Kelurahan Pudakpayung 
Bila dilihat kualitas sarana lingkungan per RW, dapat dilihat bahwa Sarana Lingkungan di Kelurahan Pudakpayung sebagian besar berkualitas kurang baik. Sarana Lingkungan yang berkualitas baik berada di RW IV, VI, X, XIII, dan XV. Sarana Lingkungan yang berkualitas kurang baik berada di RW I, II, III, VII, IX, XI, XIV, dan XVI. Sedangkan Sarana Lingkungan yang berkualitas buruk berada di RW V, VIII, dan XII.

2. Kualitas Prasarana Lingkungan sebagai berikut :

Tabel 4. Nilai Skoring Prasarana Lingkungan

\begin{tabular}{c|c|c|c|c|c|c}
\hline \multirow{2}{*}{ Keterangan } & \multicolumn{6}{|c}{ Prasarana } \\
\cline { 2 - 7 } & Drainase & $\begin{array}{c}\text { Sanitasi } \\
\text { Lingkungan }\end{array}$ & $\begin{array}{c}\text { Air } \\
\text { Bersih }\end{array}$ & Jalan & Persampahan & $\begin{array}{c}\text { Transportasi } \\
\text { Lokal }\end{array}$ \\
\hline $\begin{array}{c}\text { Total } \\
\text { Skoring }\end{array}$ & 16 & 16 & 16 & 16 & 16 & 16 \\
\hline $\begin{array}{c}\text { Jumlah } \\
\text { Unit }\end{array}$ & 47 & 48 & 36 & 38 & 43 & 16 \\
\hline $\begin{array}{c}\text { Nilai } \\
\text { Skoring }\end{array}$ & $\begin{array}{c}\mathbf{2 , 9} \\
\text { (baik) }\end{array}$ & $\mathbf{3}$ (baik) & $\begin{array}{c}\mathbf{2 , 2} \\
\text { (kurang } \\
\text { baik) }\end{array}$ & $\begin{array}{c}\mathbf{2 , 3} \\
\text { (kurang } \\
\text { baik) }\end{array}$ & $\mathbf{2 , 6}$ (baik) & $\mathbf{1}$ (buruk) \\
\hline
\end{tabular}

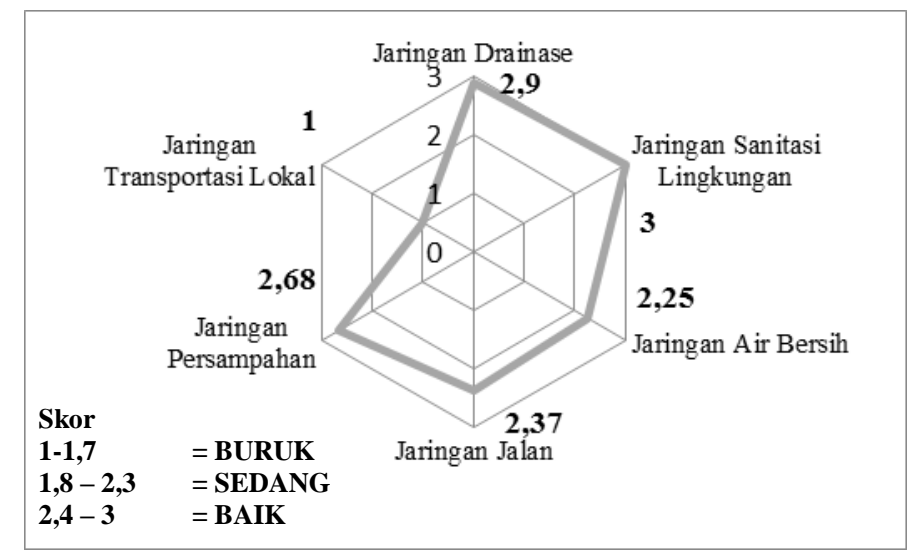

\section{Gambar 5. Diagram Analisis Kondisi Prasarana di Kelurahan Pudakpayung}

Secara keseluruhan, dapat dilihat bahwa kualitas dari jaringan drainase, jaringan sanitasi lingkungan, dan jaringan persampahan di Kelurahan Paudakpayung rata-rata sudah BAIK sedangkan kualitas jaringan air bersih dan jaringan jalan di Kelurahan Pudakpayung rata-rata masih KURANG BAIK. Sehingga perlu untuk diadakannya peningkatan kualitas untuk prasarana yang masih kurang baik, baik dari fisik maupun non fisik.

Sedangkan untuk jaringan transportasi di Kelurahan Pudakpayung memiliki nilai 1 yang menggambarkan kualitas jaringan yang BURUK. Nilai ini menggambarkan bahwa menurut sebagian besar masyarakat di Kelurahan Pudakpayung merasa keberatan dan menyayangkan akan pemberhentian angkutan umum bus yang dulunya pernah beroperasi di kawasan Kelurahan Pudakpayung. Karena selain dapat membantu masyarakat untuk pergi bekerja, sekolah, atau kegiatan pergerakan yang lain, angkutan umum bus ini juga dapat membantu mengurangi biaya 
pengeluaran yaitu biaya transportasi. Sehingga perlu untuk memperbaiki atau bahkan mengadakan jaringan transportasi lokal di Kelurahan Pudakpayung.

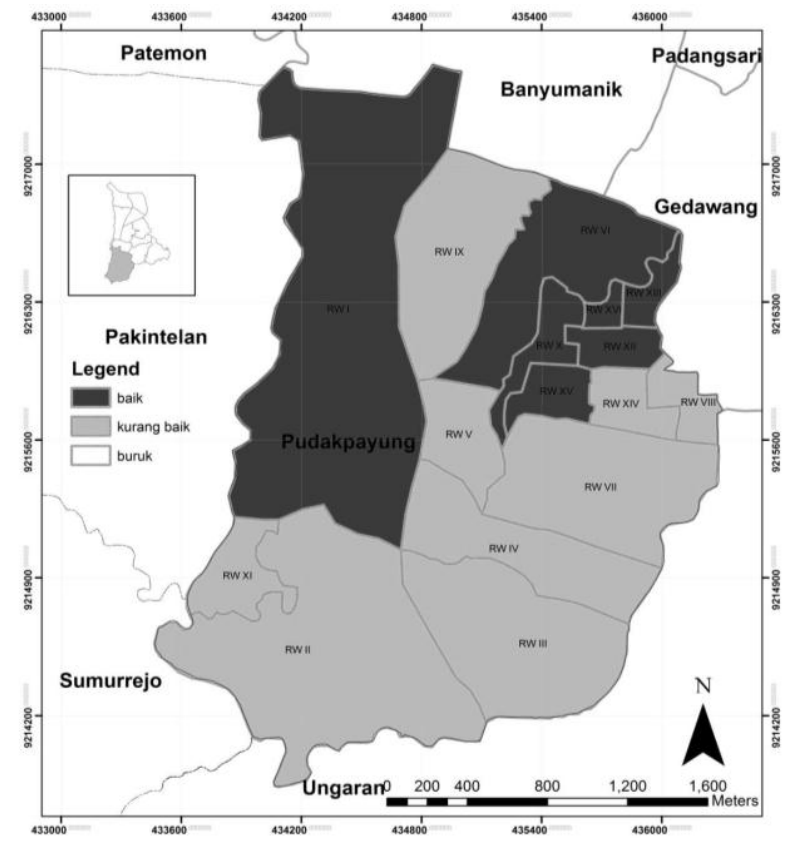

\section{Gambar 6. Peta Kualitas Prasarana Lingkungan di Kelurahan Pudakpayung}

Bila dilihat kualitas prasarana lingkungan per RW, dapat dilihat bahwa Prasarana Lingkungan di Kelurahan Pudakpayung sebagian besar berkualitas kurang baik. Prasarana Lingkungan yang berkualitas baik berada di RW I, VI, X, XII, XIII, XV, dan XVI. Sedangkan Prasarana Lingkungan yang berkualitas kurang baik berada di RW II, III, IV, V, VII, VIII, IX, X, XI, dan XIV.

\section{Analisis Persebaran Sarana Prasarana Lingkungan Permukiman}

Dari analisis persebaran sarana prasarana lingkungan permukiman yang telah dilakukan dapat diketahui bahwa:

1. Unit sarana yang telah tersebar secara merata adalah Posyandu, Puskesmas, Tempat Praktek Dokter, dan Masjid Warga. Sedangkan unit sarana yang belum tersebar secara merata adalah PAUD/ TK, SD, SLTP, SLTA, Taman Bacaan, Balai Pengobatan, Musholla/ Langgar, Gereja/ Sanggar, Vihara, Toko/ Warung, Pertokoan, Balai Warga, Gedung Serbaguna, Taman/ Tempat Bermain, Lapangan Olahraga, dan Makam.

2. Prasarana yang telah tersebar secara merata adalah Jaringan Drainase, Jaringan Sanitasi Lingkungan, Jaringan Air Bersih, dan Jaringan Jalan. Sedangkan prasarana yang belum tersebar secara merata adalah Jaringan Persampahan dan Jaringan Transportasi Lokal.

\section{Kesimpulan \& Rekomendasi}

Berdasarakan hasil analisis yang telah dilakukan, maka dapat dirumuskan kesimpulan untuk menggambarkan secara ringkas mengenai hasil penelitian. Hasil yang didapatkan menyatakan bahwa Kelurahan Pudakpayung merupakan daerah pinggiran kota yang mengalami pertumbuhan lahan terbangun yang pesat. Lahan terbangun tersebut tumbuh sebesar $8,3 \%$ pada 
tahun 2004 hingga 2009 dan 13,3\% pada tahun 2009 hingga 2014. Dan lahan terbangun tersebut didominasi oleh lahan permukiman.

Untuk ketersediaan jumlah unit sarana dan prasarana lingkungan yang sudah tersedia sesuai standar adalah PAUD/ TK, Posyandu, Puskesmas, Tempat Praktek Dokter, Masjid Warga, Gereja/ Sanggar, Vihara, Toko/ Warung, Pertokoan, Balai Warga, Gedung Serbaguna, Lapangan Olahraga, Makam, Jaringan Drainase, Jaringan Sanitasi Lingkungan, Jaringan Air Bersih, Jaringan Jalan, dan Jaringan Persampahan. Sedangkan untuk ketersediaan yang belum sesuai standar adalah SD, SLTP, SLTA, Taman Bacaan, Balai Pengobatan, Musholla/ Langgar, Taman/ Tempat Bermain, dan Jaringan Transportasi Lokal.

Untuk sarana dan prasarana lingkungan yang berkualitas baik adalah SD, SLTP, SLTA, Taman Bacaan, Puskesmas, Tempat Praktek Dokter, Musholla/ Langgar, Masjid Warga, Gereja/ Sanggar, Vihara, Toko/ Warung, Pertokoan, Gedung Serbaguna, Taman/ Tempat Bermain, Makam, Jaringan Drainase, Jaringan Sanitasi Lingkungan, Jaringan Air Bersih, dan Jaringan Persampahan. Sedangkan untuk sarana dan prasarana lingkungan yang berkualitas kurang baik adalah PAUD/ TK, Posyandu, Balai Pengobatan, Balai Warga, Lapangan Olahraga, dan Jaringan Jalan. Untuk Jaringan Transportasi Lokal yang ada di Kelurahan Pudakpayung bernilai buruk.

Dan untuk sarana dan prasarana yang sudah tersebar secara merata adalah Posyandu, Puskesmas, Tempat Praktek Dokter, Masjid Warga, Jaringan Drainase, Jaringan Sanitasi Lingkungan, Jaringan Air Bersih, dan Jaringan Jalan. Sedangkan sarana prasarana yang belum tersebar secara merata adalah PAUD/ TK, SD, SLTP, SLTA, Taman Bacaan, Balai Pengobatan, Musholla/ Langgar, Gereja/ Sanggar, Vihara, Toko/ Warung, Pertokoan, Balai Warga, Gedung Serbaguna, Taman/ Tempat Bermain, Lapangan Olahraga, Makam, Jaringan Persampahan, dan Jaringan Transportasi Lokal.

Dari hasil yang didapatkan kemudian dipelukan adanya upaya untuk menyelesaikan setiap kekurangan yang ada, berikut rekomendasinya:

- Berdasarkan analisis pola perubahan lahan permukiman, terjadi peningkatan lahan terbangun di Kelurahan Pudakpayung setiap tahunnya. Dan akan terus bertambah setiap tahunnya, sehingga perlu untuk membatasi luas lahan terbangun dan luas lahan tidak terbangun, mengingat bahwa sudah menipisnya RTH di Kota Semarang.

- Berdasarakan analisis ketersediaan sarana prasarana lingkungan permukiman, perlu untuk diperhatikan jumlah unit tiap sarana sesuai SNI yang sudah berlaku. Pemenuhan kebutuhan masyarakat akan sarana dan prasarana perlu untuk diperhatikan karena sarana dan prasarana ini merupakan prinsip dasar dalam bermukim. Seperti masih kurang 11 unit SD, 2 unit SLTP, 3 unit SLTA, 4 unit Taman Bacaan, 8 unit Balai Pengobatan, 74 unit Musholla, dan 6 atau 85 unit Taman/ Tempat Bermain lagi. Sedangkan untuk ketersediaan dari prasarana lingkungan permukiman di Kelurahan Pudakpayung perlu diperhatikan kembali akan Jaringan Transportasi Lokal yang kini sudah tidak beroperasi lagi, tetapi permintaan dari masyarakat cukup tinggi.

- Berdasarkan analisis kualitas sarana prasarana lingkungan permukiman, perlu untuk dilakukannya peningkatan kualitas dan mutu dari bangunan PAUD/ TK, Posyandu, Balai Pengobatan, Balai Warga, dan Lapangan Olahraga, baik dari sisi fisik dan non fisik. Serta perlu untuk memperhatikan kualitas dan mutu dari Jaringan Jalan dan Jaringan Air Bersih yang saat ini masih kurang baik. Perlu adanya perbaikan di hampir semua sisi jalan dan pemerataan untuk sumber air bersih sehingga masyarakat di Kelurahan Pudakpayung tidak kesulitan lagi. Dan juga untuk kualitas dari Jaringan Transportasi Lokal yang sekarang telah berhenti beroperasi.

- Berdasarkan analisis persebaran sarana lingkungan permukiman, perlu untuk diperhatikan persebarannya. Terutama persebaran dari PAUD/ TK, SD, SLTP, SLTA, Taman Bacaan, Balai Pengobatan, Musholla/ Langar, Gereja/ Sanggar, Vihara, Toko/ Warung, Pertokoan, Balai Warga, Gedung Serbaguna, Taman/ Tempat Bermain, Lapangan Olahraga, Makam, Jaringan Persampahan, dan Jaringan Transportasi Lokal. 
- Walaupun secara penilaian berdasarkan SNI masih banyak kekurangan sarana di Kelurahan Pudakpayung, tetapi dalam pemenuhannya dibutuhkan kajian lebih lanjut terkait dengan fungsi dan manfaat dari setiap sarana. Begitupun dengan aspek rasionalitas yang perlu untuk diperhatikan dalam memenuhi segala kebutuhan akan sarana dasar tersebut.

- Dan yang terakhir bukan hanya pemerintah yang berkewajiban untuk menyediakan sarana dan prasarana dengan kualitas yang baik dan persebaran yang merata, masyarakat juga harus mampu menjaga kualitas dan keberlanjutan dari sarana dan prasarana lingkungan yang telah dibuat. Selain itu, masyarakat juga harus mampu hidup mandiri yang kreatif agar tidak terlalu bergantung kepada pusat kota. Sedangkan untuk potensi lokal yang telah dimiliki dapat untuk terus dipertahankan dan ditingkatkan sehingga menjadi identitas daerah.

\section{Daftar Pustaka}

Azahro, Mustovia. 2013. "Kajian Kehidupan Masyarakat Kampung Lama Sebagai Potensi Keberlanjutan Lingkungan Permukiman Kelurahan Gabahan Semarang” Jurnal PWKVol. 2, No. 3. Semarang: UNDIP

Badan Standarisasi Nasional. 2004. Tata Cara Perencanaan Lingkungan Perumahan Di Perkotaan. Bandung: Badan Standarisasi Nasional

Badan Pusat Statistik. 2011. Kecamatan Banyumanik dalam Angka 2011. Semarang: Badan Pusat Statistik Kota Semarang.

Budihardjo, Eko. 1991. Fenomena Metropolis \& Megapolis: Kepadatan dan Bangunan Tinggi. Jakarta: IMA Universitas Taruma Negara. 1998. Sejumlah Masalah Pemukiman Kota. Bandung: PT Alumni Bandung.

Budihardjo, Eko dan Sudanti Hardjohubojo. 1993. Kota Berwawasan Lingkungan. Bandung: PT Alumni Bandung.

Kisaz, Marrio. 2011. Meretas batas, bersolek keterisolasian dalam www.m.riaupos.co. Diunduh hari jumat tanggal 28 Februari 2014. Pukul 15.40.

Silondae. Irhansyah Umar. 2010. Kondisi Lingkungan Perumahan Dalam Kontek Kenyamanan Hidup. Tugas Akhir Jurusan Perencanaan Wilayah dan Kota. Semarang: UNDIP.

Sugiyono. 2013. Metode Penelitian Pendidikan Pendekatan Kuantitatif, Kualitatif dan R\&D. Bandung: Alfabeta

UU RI No. 1 tahun 2011 tentang Perumahan dan Kawasan Permukiman.

Yunus, Hadi Sabari. 2008. Dinamika Wilayah Peri-Urban Determinan Masa Depan Kota. Yogyakarta: Pustaka Belajar. 